\title{
Influence of Mechanical Cycling on Residual Strain in Superelastic Cu-Al-Be-Nb Alloys
}

\author{
Danniel Ferreira de Oliveira ${ }^{a, b} * \mathbb{1}^{-}$, Ieverton Caiandre Andrade Brito ${ }^{b}$, Rafael Evaristo Caluête ${ }^{c}$, \\ Rodinei Medeiros Gomes ${ }^{a, c}$, Tadeu Antônio de Azevedo Melo ${ }^{c}$ \\ a'Programa de Pós-Graduação em Ciência e Engenharia de Materiais, Universidade Federal da \\ Paraíba, João Pessoa, PB, Brasil \\ ${ }^{b}$ Departamento de Engenharia de Materiais, Universidade Federal da Paraíba, João Pessoa, PB, Brasil \\ ${ }^{c}$ Departamento de Engenharia Mecânica, Universidade Federal da Paraíba, João Pessoa, PB, Brasil
}

Received: January 30, 2019; Revised: April 12, 2019; Accepted: May 20, 2019

\begin{abstract}
The understanding of the stabilization mechanism of martensite used to obtain alloys with high hysteresis and the possibility of recovering this martensite (residual strain) by heating at temperatures higher than $\mathrm{A}_{\mathrm{s}}$ and $\mathrm{A}_{\mathrm{f}}$ have been fundamental for application in bonding devices. One of the possibilities to enhance residual strain is through mechanical cycling. This work evaluated the influence of number of cycles and the effect of precipitation of $\mathrm{Nb}$-rich particles as mechanisms to increase residual strain in superelastic $\mathrm{Cu}-\mathrm{Al}-\mathrm{Be}-\mathrm{Nb}$ alloys. The results showed that the presence of $\mathrm{Nb}$-rich precipitates was not a predominant factor for the enhancement of residual strain. In addition, mechanical cycling has proved to be an efficient mechanism for raising residual strain, and consequently increasing the amount of martensite retained. However, the gain of residual strain is accompanied by an increase of plastic deformation.
\end{abstract}

Keywords: Residual strain, martensite retained, mechanical cycling.

\section{Introduction}

In many practical cases of application using shape memory alloys (SMAs), such as rivets, pipe connections, aeronautical industry devices, etc., it is necessary that the starting temperature of the martensitic transformation, $M_{s}$, occur in bands temperature below $0^{\circ} \mathrm{C}$. However, due to the need for low temperatures $\left(\mathrm{M}_{\mathrm{s}}<0{ }^{\circ} \mathrm{C}\right)$, for these applications, the storage and installation of these devices must be carried out in cryogenic media, resulting in high cost of use $e^{1,2,3}$. One way to solve this problem would be to use alloys with a higher thermal hysteresis (difference between $\mathrm{M}_{\mathrm{s}}$ and $A_{s}$ temperatures). Thus, the alloy could be deformed and stored at higher temperatures (temperature lower than $\mathrm{A}_{\mathrm{s}}$ ), considerably reducing the costs of storing the components.

The increase of the thermal hysteresis of the SMAs can be obtained through mechanisms that stabilize the martensitic phase. The pre-deformation of the austenite phase has been employed in recent years as a mechanism capable of stabilizing the martensite phase, resulting in the elevation of the thermal hysteresis of $\mathrm{Cu}-\mathrm{Al}^{1,4}$ and $\mathrm{Ni}-\mathrm{Ti}^{5,6,7}$ based alloys. Oliveira et. al. ${ }^{8}$ have observed that low strain rates applied during pre-deformation of $\mathrm{Cu}-\mathrm{Al}-\mathrm{Be}-\mathrm{Nb}$ alloys are capable to improve residual strain, causing a significant increase in stabilized martensite.

Another feasible possibility to increase the percentage of residual strain in the SMAs is the application of predeformation cycles. Saint-Sulpice et. al. ${ }^{9}$ verified through cyclic loading and unloading tests in a $\mathrm{Cu}-\mathrm{Al}-\mathrm{Be}$ alloy the appearance of residual strain immediately after the first cycle, reaching a limit value as the number of cycles increases.

Oliveira et. al. ${ }^{10}$ evaluated the evolution of unrecoverable deformation with the number of loading/unloading cycles for a laser welded $\mathrm{Cu}-\mathrm{Al}-\mathrm{Be}$ alloy and observed that only one loading/unloading cycle is required to obtain a stabilization of the cyclic mechanical behavior, i.e, the evolution of irrecoverable deformation and mechanical hysteresis between consecutive cycles is minimal.

Different explanations for the stabilization of martensite caused by pre-deformation have been proposed. For example, for the $\mathrm{Cu}-\mathrm{Al}-\mathrm{Mn}$ alloys, $\mathrm{Li}$ et. al. ${ }^{1}$ proposed that the stress induced transformation is accompanied by actual plastic deformation of the austenite phase. In this way, the elastic interfaces of martensite are seriously damaged and the transformation hysteresis increases.

In the case of $\mathrm{Ni}-\mathrm{Ti}-\mathrm{Nb}$ alloys, especially, there are antagonistic versions to explain the phenomenon of stabilization of martensite by pre-deformation. According to He et. al. ${ }^{11}$, the large amount of $\mathrm{Nb}$ precipitates in the $\mathrm{Ni}-\mathrm{Ti}$ alloys are responsible for the increase of the residual strain, as well as for the increase in the thermal hysteresis of the alloy. On the other hand, Zhao et. al. ${ }^{5}$, found that the niobium precipitates do not influence the enhacement of thermal hysteresis and the niobium dissolved in the $\mathrm{Ni}-\mathrm{Ti}$ alloy matrix is responsible for it. 
Guniputi and Murigendrappa ${ }^{12}$ reported that increasing the Gd content above $0.1 \%$ (wt.\%) in the $\mathrm{Cu}-\mathrm{Al}-\mathrm{Be}-\mathrm{Gd}$ alloy causes high insolubility in the matrix and promotes formation of precipitate and intermetallic agglomeration. In addition, the shape recovery of Gd-doped $\mathrm{Cu}$-Al-Be alloys decreased from 97 to $65 \%$, with the increases of gadolinium content, due to the insoluble gadolinium that impedes the mobility of the martensite variants.

Recently, X-ray diffraction and neutron methods have been applied to investigate the mechanisms associated with stress-induced martensitic transformation in superelastic SMAs ${ }^{13,14,15}$. According to Sedmák et. al. ${ }^{15}$ the instability of the superelastic behavior, during cyclical stress-strain tests, occurs due to the gradual redistribution of internal stresses caused by accumulation of additional plastic deformations accompanied by stress induced martensitic transformation in a restricted polycrystalline environment.

In addition to the mechanism involved in the stabilization of martensite, the possibility of recovering martensite retained (residual strain) by heating at temperatures $\left(\mathrm{A}_{\text {s-rev }}\right.$ and $\left.\mathrm{A}_{\text {f-rev }}\right)$ much higher than $\mathrm{A}_{\mathrm{s}}$ (beginning of the austenitic transformation) and $\mathrm{A}_{\mathrm{f}}$ (the end of the austenitic transformation), has been fundamental for application in union devices. Oliveira et. Al. ${ }^{8}$ have effectively used a pipe ring with residual strain to join pipes. These couplings exhibited a clamping force as high as that of couplings obtained by the memory effect in conventional manner.

In this sense, the main objective of this work is to evaluate the influence of the number of loading/unloading cycles as a mechanism to increase residual strain in superelastic $\mathrm{Cu}-\mathrm{Al}$ $\mathrm{Be}-\mathrm{Nb}$ alloys. Furthermore, the possibility of reversion of this residual strain by heating at zero load after the mechanical pre-deformation cycles as well as the effect of precipitation of $\mathrm{Nb}$-rich particles on the reverse transformation of the induced martensite were evaluated.

\section{Experimental Procedures}

Approximately $450 \mathrm{~g}$ of the alloys with nominal composition $\mathrm{Cu}-11.8 \mathrm{Al}-0.6 \mathrm{Be}-0.5 \mathrm{Nb}$ (wt.\%) and $\mathrm{Cu}-11.8 \mathrm{Al}-0.6 \mathrm{Be}-4 \mathrm{Nb}$ (wt.\%) were melted by induction in a graphite crucible without atmosphere control. After casting, the alloys were solidified conventionality using gravity casting process in a metal die and then homogenized at $850{ }^{\circ} \mathrm{C}$ for $24 \mathrm{~h}$. Before to the tensile test, the samples were heated at $850{ }^{\circ} \mathrm{C}$ for $1 \mathrm{~h}$ and then quenched in water until reachs de temperature of $25^{\circ} \mathrm{C}$. The specimens used in the cyclic tensile tests are shown in Figure 1. It is important notice that the device for accommodating the specimens ensures that there is no slippage during the tensile test.

The tensile tests were performed on a test machine (Servopulser Shimadzu $50 \mathrm{KN}-\mathrm{EHF}$ ) equipped with a heating and cooling chamber. The residual strain was quantified by loading and unloading cycles with deformations of $4.5 ; 5$

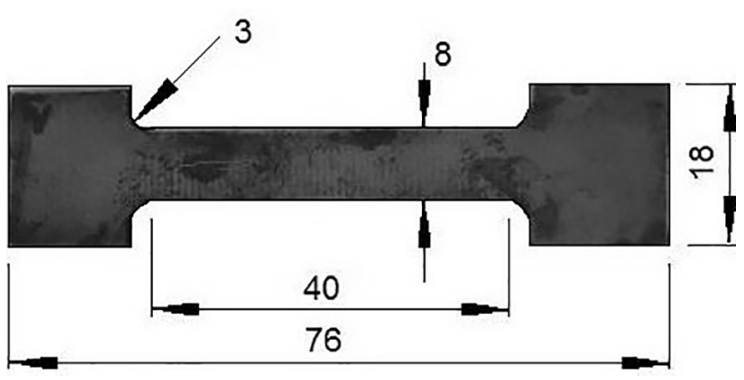

Figure 1. Sample used to mechanical test. Dimensions in (mm).

and $6 \%$ at different temperatures and strain rate of $0.004 \mathrm{~s}^{-1}$. Samples were deformed at predefined values with constant test temperature. After the deformation, the load was removed until the stress reached a value of zero. Besides that, for each condition, the shape recovery by heating the specimen at zero load after the mechanical pre-deformation cycles were quantified.

Solid state reactions were investigated by differential scanning calorimetry (Shimadzu DSC-60) using a heating and cooling rate of $10^{\circ} \mathrm{C} \cdot \mathrm{min}^{-1}$ under nitrogen atmosphere. The microstructure was investigated by optical microscopy and atomic force techniques to evaluate the presence of martensite retained after the cyclic tensile tests.

\section{Results and Discussion}

Figures $2 \mathrm{a}$ and $2 \mathrm{~b}$ show the micrographs of the alloys $\mathrm{Cu}-11.8 \mathrm{Al}-0.6 \mathrm{Be}-0.5 \mathrm{Nb}$ (wt.\%) and $\mathrm{Cu}-11.8 \mathrm{Al}-0.6 \mathrm{Be}-$ $4 \mathrm{Nb}$ (wt.\%), respectively. It is possible notice a great amount of precipitates for the alloy with $4 \% \mathrm{Nb}$, which certainly are rich in $\mathrm{Nb}$, element that presents/displays low solubility in the austenitic matrix ${ }^{16}$. $\mathrm{Nb}$ precipitates in $\mathrm{Ni}-\mathrm{Ti}$ alloys are responsible for increasing hysteresis under pre-deformation conditions, where $\beta-\mathrm{Nb}$ particles act as a block to reverse martensitic transformation after unloading ${ }^{11}$.

Lelatko et. al. ${ }^{17}$ reported that for contents above $2.56 \%$ (wt.\%) of niobium in the $\mathrm{Cu}-\mathrm{Al}-\mathrm{Nb}$ alloy the particle size in the high temperature phase decreases and the fine particles of primary phase segregate predominantly along the limits of grain. Besides that, they observed the degree of shape recovery of $\mathrm{Cu}-\mathrm{Al}-\mathrm{Nb}$ alloys decreases with increasing $\mathrm{Nb}$ content from $2.56 \%$ to $7.86 \%$ (wt. $\%$ ).

In addition to the influence of $\mathrm{Nb}$ precipitation on the microstructure of the $\mathrm{Cu}-\mathrm{Al}-\mathrm{Be}-\mathrm{Nb}$ alloys, the effect on the phase transformation temperatures of these alloys, which are presented in Table 1, was also evaluated. When comparing the austenitic and martensitic transformation temperatures of $\mathrm{Cu}-11.8 \mathrm{Al}-0.6 \mathrm{Be}-4 \mathrm{Nb}$ (wt.\%) alloy with $\mathrm{Cu}-11.8 \mathrm{Al}$ $0.6 \mathrm{Be}-0.5 \mathrm{Nb}$ (wt.\%) alloy, it is possible to observe that these temperatures increase, perhaps due to the formation of niobium precipitates. 


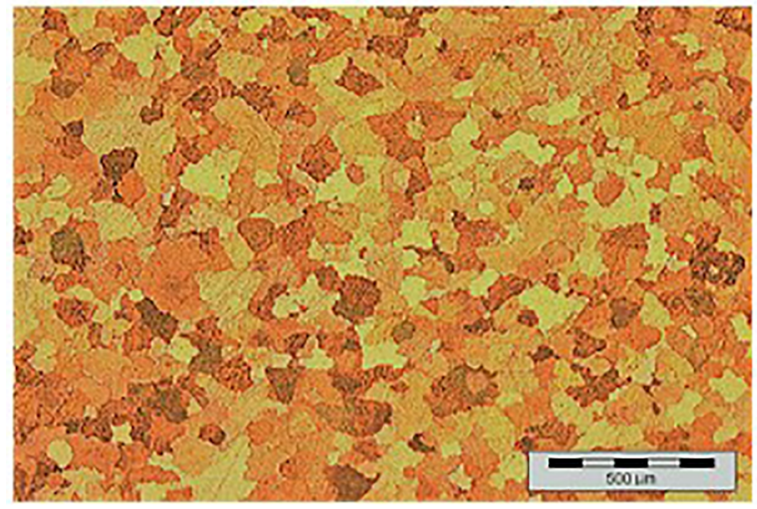

(a)

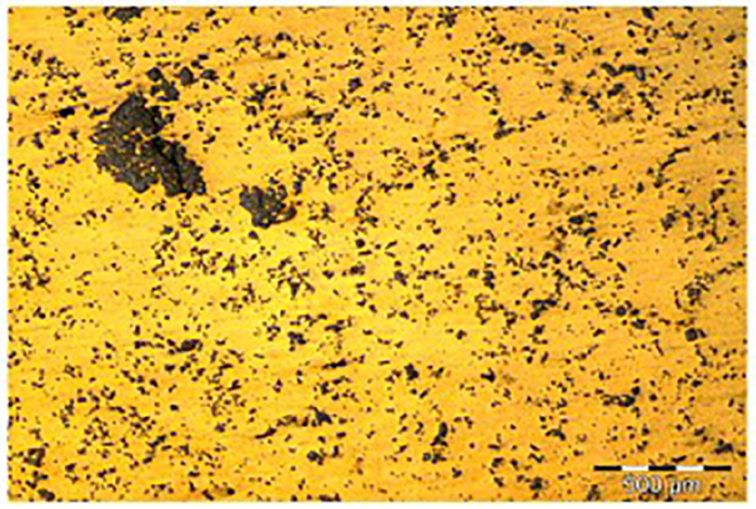

(b)

Figure 2. (a) Presence of austenite in the alloy $0.5 \mathrm{Nb}$ and (b) precipitates of $\mathrm{Nb}$ (black points) in austenitic phase (yellow background) in the alloy with $4 \mathrm{Nb}$.

Table 1. Phase transformation temperatures for alloys.

\begin{tabular}{ccccc}
\hline Alloys & $\mathrm{M}_{\mathrm{s}}\left({ }^{\circ} \mathrm{C}\right)$ & $\mathrm{M}_{\mathrm{f}}\left({ }^{\circ} \mathrm{C}\right)$ & $\mathrm{A}_{\mathrm{s}}\left({ }^{\circ} \mathrm{C}\right)$ & $\mathrm{A}_{\mathrm{f}}\left({ }^{\circ} \mathrm{C}\right)$ \\
\hline $\begin{array}{c}\mathrm{Cu}-11.8 \mathrm{Al}-0.6 \mathrm{Be}- \\
0.5 \mathrm{Nb}\end{array}$ & -63 & -83 & -48 & -34 \\
$\begin{array}{c}\mathrm{Cu}-11.8 \mathrm{Al}-0.6 \mathrm{Be}- \\
4 \mathrm{Nb}\end{array}$ & -5 & -30 & 0 & 45 \\
\hline
\end{tabular}

Another element of low solubility in the $\mathrm{Cu}-\mathrm{Al}$ alloy matrix is $\mathrm{Cr}$, which as observed by Candido et. al. ${ }^{18}$, promotes a significant change in the phase transformation temperatures of $\mathrm{CuAlBe}$ alloys. The authors associated an gradual increase of the transformation temperatures to the formation of precipitates containing $\mathrm{Cr}$ and $\mathrm{Be}$ and the subsequent reduction of the content of $\mathrm{Be}$ in the matrix. Specifically for $\mathrm{Cu}-\mathrm{Al}-\mathrm{Be}$ alloys, $\mathrm{Nb}$-rich precipitates are also rich in $\mathrm{Al}^{16}$. It is important to say that the decrease in $\mathrm{Al}$ concentrations in austenitic matrix causes an enhancement in the temperatures of phase transformations ${ }^{19}$.

To evaluate the influence of $\mathrm{Nb}$ precipitates on residual strain of $\mathrm{CuAlBeNb}$ alloys, tensile loading/unloading tests were performed in both alloys studied in this work. The same strain rates and a $\mathrm{Ms}+30{ }^{\circ} \mathrm{C}$ test temperature were used. Thus, the amount of niobium precipitate in the matrix was not a predominant factor for an increase in the amount of residual strain, as shown in Figure 3. It can be observed in Figure 3 that to produce the same level of deformation (specifically $6 \%$ in this work) the required stress is lower for the alloy with $4 \% \mathrm{Nb}$. Similar result was obtained by Zhao et. al. ${ }^{5}$ for Ni-Ti alloys.

It was also investigated the evolution of the residual strain with the number of cycles for both alloys. Figures 4 and 5 show the results of a strain-strain test with 3 cycles of loading and unloading at $0^{\circ} \mathrm{C}$ for alloys with $0.5 \mathrm{Nb}$ and $4 \mathrm{Nb}$, respectively. Figures 4 and 5 shows a decrease in the martensite induction stress as the number of loading/unloadig cycles increases. On the other hand, there were no significant changes in residual

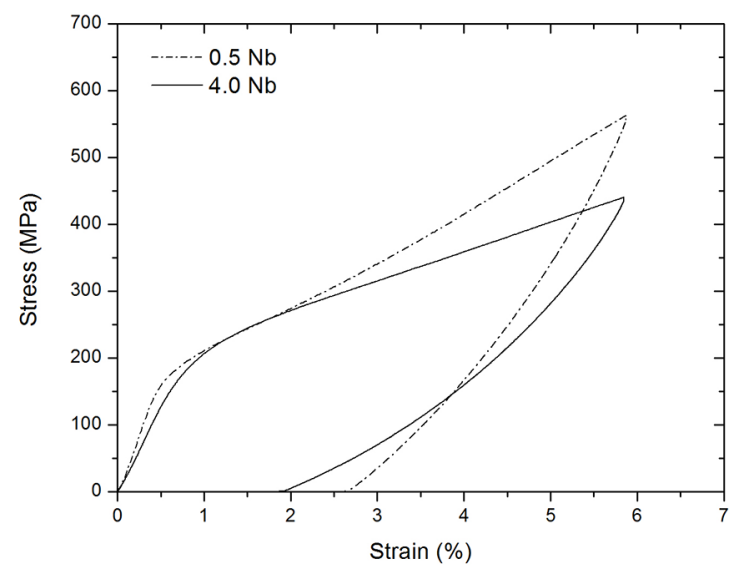

Figure 3. Test for the quantification of superelasticity at the temperature of $\mathrm{Ms}+30{ }^{\circ} \mathrm{C}$ for $\mathrm{Cu}-11.8 \mathrm{Al}-0.6 \mathrm{Be}-0.5 \mathrm{Nb}$ (wt. $\%$ ) and $\mathrm{Cu}-11.8 \mathrm{Al}-0.6 \mathrm{Be}-4 \mathrm{Nb}$ (wt.\%) alloys.

strain values, around $0.4 \%$, for both alloys between the first and third cycle. A increase in residual strain is related to the phenomenon known as anchoring of dislocations, that reduces the degree of regularity in the microstructure ${ }^{20}$, hindering the path of the reverse transformation and consequently causing martensite stabilization.

Furthermore, it is possible to observe a non-zero residual stress after unloading for alloy with $4 \% \mathrm{Nb}$, probably caused by heterogeneity in the grain's deformation. This fact can be understood with the aid of the bicrystalline model reported by sedmak et. al. ${ }^{14}$. The model consists in a bicristal with neighboring grains and different crystallographic orientations separated by an interface parallel to loading directions and simplifies the behavior for a polycrystalline wire.

In addition, both alloys were subjected to repetitive loading/unloading cycling tests in order to evaluate the number of cycles required to obtain the maximum residual strain. For this, the alloy with $0.5 \% \mathrm{Nb}$ was subjected to 


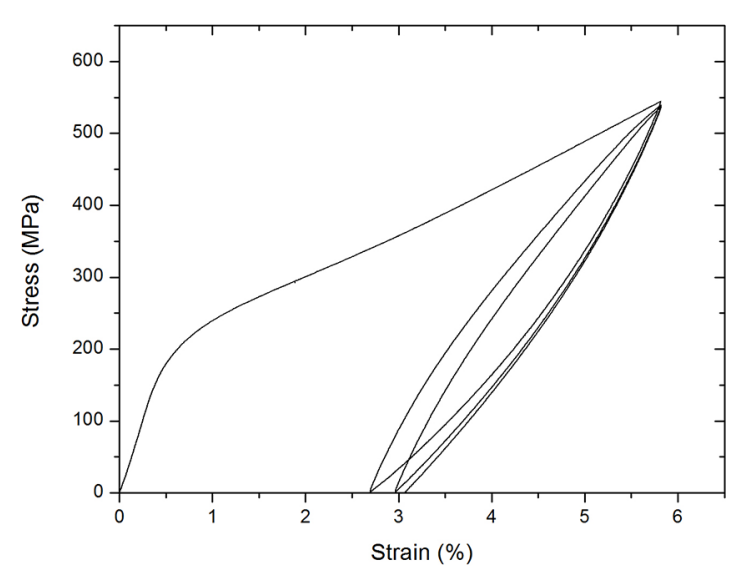

Figure 4. Test for quantification of superelasticity at $0{ }^{\circ} \mathrm{C}$ with 3 cycles of strain for $\mathrm{Cu}-11.8 \mathrm{Al}-0.6 \mathrm{Be}-0.5 \mathrm{Nb}$ (wt.\%) alloy.

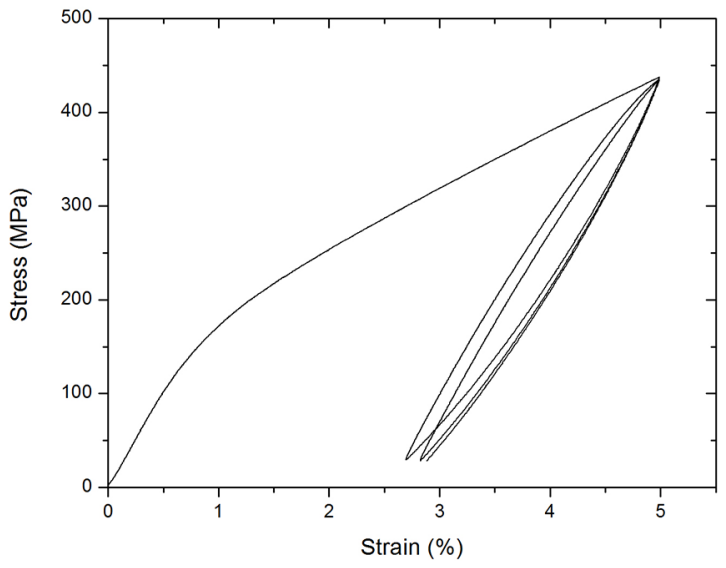

Figure 5. Test for quantification of superelasticity at $0{ }^{\circ} \mathrm{C}$ with 3 cycles of strain for $\mathrm{Cu}-11.8 \mathrm{Al}-0.6 \mathrm{Be}-4 \mathrm{Nb}$ (wt.\%) alloy.

40 cycles while the alloy with $4 \% \mathrm{Nb}$ was submitted to 10 cycles, both tests were performed at $25^{\circ} \mathrm{C}$.

According to Figure 6 it is possible to verify that the alloy with $0.5 \% \mathrm{Nb}$ has an approximate residual strain of $0.64 \%$ in the first cycle, $1.22 \%$ in the fourth cycle and finally, $1.75 \%$ in the last cycle. Therefore, it is easy to prove that in the first four cycles the same amount of residual strain was obtained than in the last 36 mechanical cycles.

For the alloy with $4 \% \mathrm{Nb}$, Figure 7 , a residual strain of approximately $1.4 \%$ is observed in the first cycle and this value increases to $1.9 \%$ after the third cycle. At long last, residual strain increases to $2.2 \%$ at the end of the ten cycles.

Figures 8 and 9 show the profile of the residual strain evolution curve as a function of the number of cycles for $\mathrm{Cu}-11.8 \mathrm{Al}-0.6 \mathrm{Be}-0.5 \mathrm{Nb}$ (wt.\%) and $\mathrm{Cu}-11.8 \mathrm{Al}-0.6 \mathrm{Be}-4 \mathrm{Nb}$ (wt.\%) alloys, respectively. It is possible to notice that, with the increase in the number of cycles, the residual strain also increases, tending to a constant value and the increment of residual strain after 10 cycles was practically the same for both alloys. According to Saint-Sulpice et. al. ${ }^{21}$ the behavior

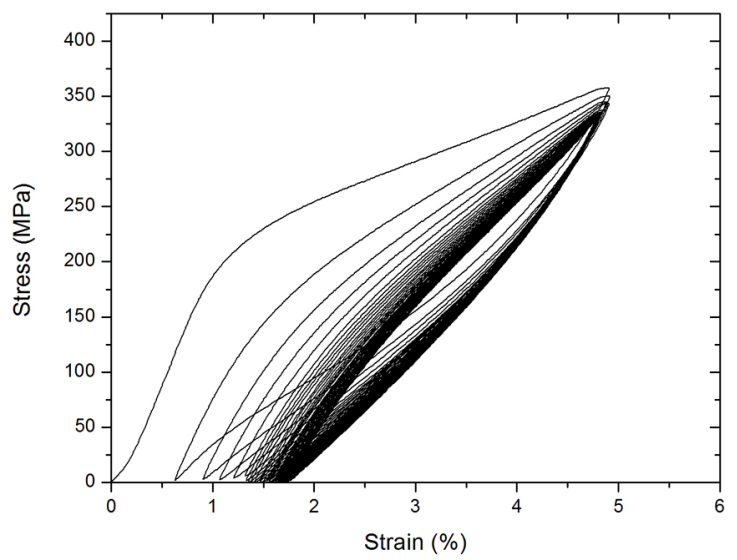

Figure 6. Test for the quantification of the superelasticity at the temperature of $25^{\circ} \mathrm{C}$ with 40 cycles of deformation for $\mathrm{Cu}-11,8 \mathrm{Al}-$ $0,6 \mathrm{Be}-0,5 \mathrm{Nb}$ (wt.\%) alloy.

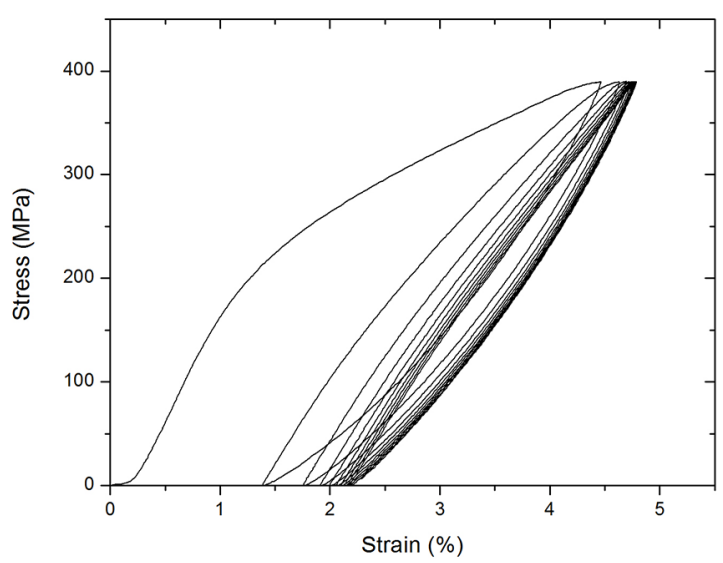

Figure 7. Test for the quantification of the superelasticity at the temperature of $25^{\circ} \mathrm{C}$ with 10 cycles of deformation for $\mathrm{Cu}-11.8 \mathrm{Al}$ $0.6 \mathrm{Be}-4 \mathrm{Nb}$ (wt.\%) alloy.

of the residual strain in a $\mathrm{Cu}-\mathrm{Al}$-Be alloy subjected to loadunload cycles with constant strain amplitude increases with the number of cycles until reaching a saturation value. According to the authors, this value depends on the amplitude of the deformation applied, i.e, residual strain is higher as high deformations is applied.

The degradation of the superelastic properties with the increase in the number of cycles indicates a enhance of the density of dislocations and/or the amount of stabilized martensite ${ }^{22}$. This superelastic behavior presents a strong dependence on the test temperature, the strain rate and the strain amplitude.

The increase in residual strain with the number of cycles for a polycrystalline $\mathrm{Cu}-\mathrm{Al}-\mathrm{Be}$ alloy was evaluated by Malard et. al. ${ }^{12}$. The alloy was subjected to deformation of the order of $8 \%$ to activate plastic deformation, through the mechanism of slip of dislocation. The authors observed that residual strain increases slowly from the second cycle, suggesting that most of the plastic deformation occurs already 


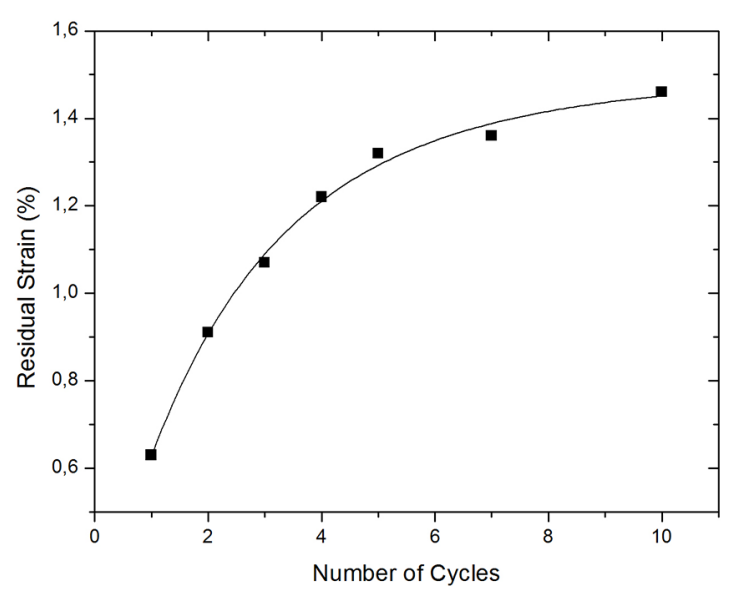

Figure 8. Residual strain as a function of the number of cycles for alloy $\mathrm{Cu}-11.8 \mathrm{Al}-0.6 \mathrm{Be}-0.5 \mathrm{Nb}$ (wt.\%) at a temperature of $25^{\circ} \mathrm{C}$.

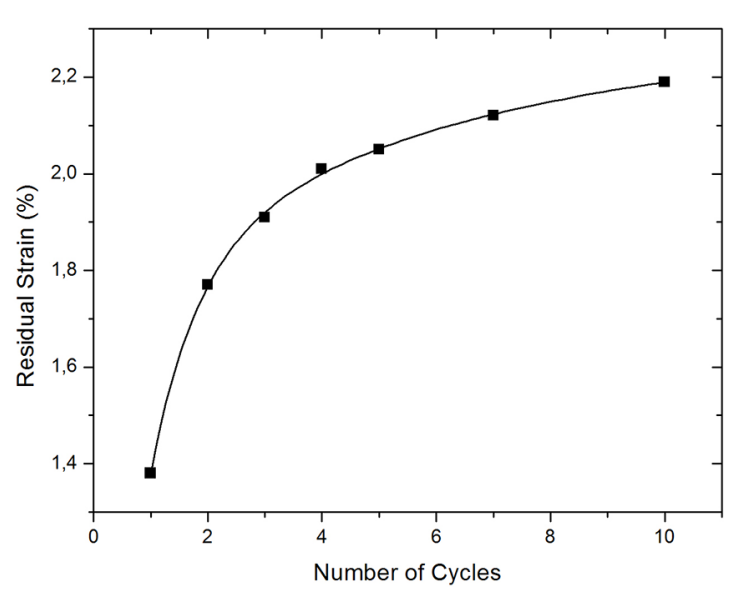

Figure 9. Residual strain as a function of the number of cycles for alloy $\mathrm{Cu}-11.8 \mathrm{Al}-0.6 \mathrm{Be}-4 \mathrm{Nb}(\mathrm{wt} . \%)$ at a temperature of $25^{\circ} \mathrm{C}$.

in the first cycle and that internal stresses are introduced into material's microstructure.

According to Sedmak et. al. ${ }^{15}$ cyclic instability in superelastic $\mathrm{Ni}$-Ti alloys occurs due to the gradual redistribution of internal stresses originated from the accumulation of plastic deformation acompanying the stress-induced martensitic transformation in a polycrystal.

The confirmation that part of the residual strain after the loading and unloading tests is associated with the retained martensite was verified from microstructural analysis by optical and atomic force microscopy.

The images of the microstructure of the specimen after the loading/unloading test with $5 \%$ deformation at the temperature of $25^{\circ} \mathrm{C}$, obtained by light microscopy, is showed in Figure 10. In the deformed region of the specimen, we can observe that part of the martensite (greater concentration in the circulated regions) induced by tension during the test is retained in the austenitic matrix even after unloading, therefore, residual martensite. The residual martensite present in the useful part of the specimen was also observed through atomic force microscopy, as shown in Figure 11. It is possible to observe the presence of residual martensite in two and three dimensions. It was also verified that the martensite plates have similar heights and with the same orientation for the analyzed region. This result indicates the presence of a single variant of martensite in the area under analysis.

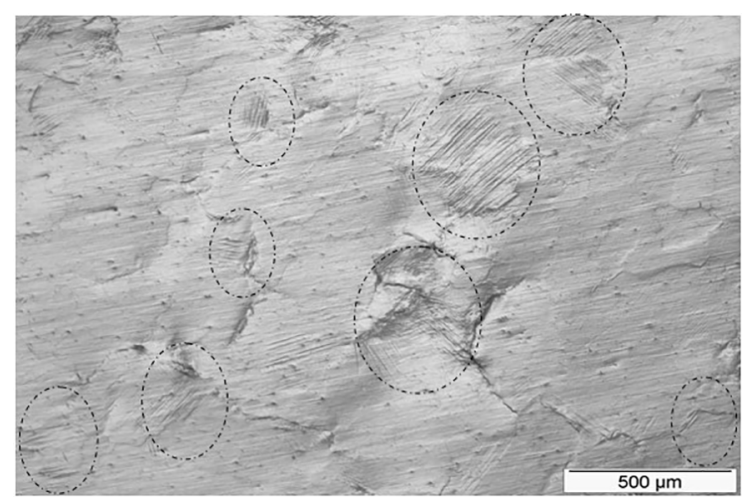

Figure 10. Areas of residual martensite after $5 \%$ deformation cycle for alloy $\mathrm{Cu}-11.8 \mathrm{Al}-0.6 \mathrm{Be}-0.5 \mathrm{Nb}$ (wt.\%) at a temperature of $25^{\circ} \mathrm{C}$.

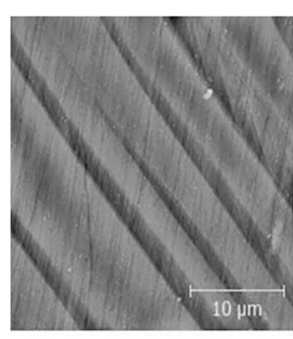

(a)

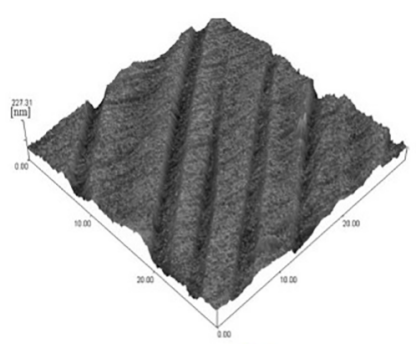

(b)
Figure 11. AFM images of a sample that has been subjected to 1 loading/unloading cycle for alloy $\mathrm{Cu}-11.8 \mathrm{Al}-0.6 \mathrm{Be}-0.5 \mathrm{Nb}$ (wt.\%) at a temperature of $25^{\circ} \mathrm{C}$. (a) 2D. (b) $3 \mathrm{D}$.

As observed, the behavior of residual deformation with increase of the number of cycles was similar for both alloys studied in the present work. However, the large amount of $\mathrm{Nb}$-rich precipitate presented in the $4 \% \mathrm{Nb}$ alloy was not sufficient to promote a residual deformation higher than that obtained by the alloy with $0.5 \% \mathrm{Nb}$.

Furthermore, the martensitic transformation temperatures of the alloy with $4 \% \mathrm{Nb}$ are higher than those for $0.5 \% \mathrm{Nb}$. The results demonstrated that induction stress for both alloys is dependent on the temperature at which the mechanical cycling test is performed. As verified, this induction stress increased with the increase of temperature.

Oliveira et. al. ${ }^{8}$ observed a stress-recovery stress induced martensite, after heating at $200{ }^{\circ} \mathrm{C}$, practically equivalent to the induction stress of the martensitic transformation. According to Cladera et. al. ${ }^{23}$, to avoid any loss of recovery 
stress after cooling, the temperature $\mathrm{A}_{\mathrm{f}}$ should be below room temperature.

In this way, the evolution of the residual deformation and the recovered deformation (after heating at $200{ }^{\circ} \mathrm{C}$ ) was evaluated only for the alloy with $0.5 \% \mathrm{Nb}$, considering that this alloy presented induction stress, at the same test temperature, greater than that presented by the alloy with $4 \% \mathrm{Nb}$. Moreover, the temperature $\mathrm{A}_{\mathrm{f}}$ of the alloy with $4 \%$ $\mathrm{Nb}$ is above room temperature $\left(25^{\circ} \mathrm{C}\right)$.

Figure 12 shows the evolution of residual strain and deformation recovered (after heating at $200{ }^{\circ} \mathrm{C}$ ) with $\mathrm{Cu}$ 11.8Al-0.6Be-0.5 Nb (wt. \%) alloy temperature. Three loading and unloading cycles with a maximum deformation of $6 \%$ were applied. It is verified that the residual strain decreases with the increase of temperature, while the recovered deformation presents a maximum value in the temperature of $-30{ }^{\circ} \mathrm{C}$. As observed by He and Rong ${ }^{24}$ the reverse transformation temperature of the induced martensite increases with the increase of the imposed deformation until reaching a maximum value and then decreases with the deformation.

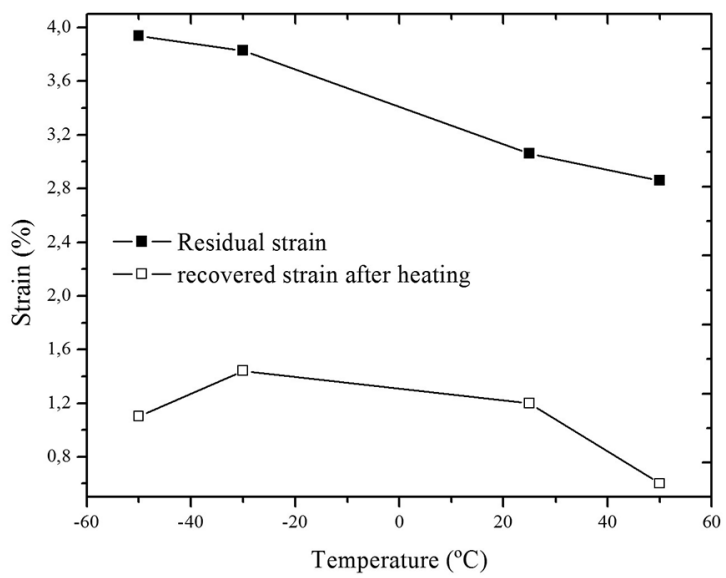

Figure 12. Residual strain and deformation recovered after heating as a function of temperature for $\mathrm{Cu}-11.8 \mathrm{Al}-0.6 \mathrm{Be}-0.5 \mathrm{Nb}$ (wt.\%) alloy.

With the increase in the number of cycles it was possible to obtain a greater residual strain, but it is verified that the residual strain recovered through the heating is less than half of the residual strain after unloading. This result indicates that a considerable part of the residual strain can be constituted of plastic deformation ${ }^{25}$. Sedmák et. al. ${ }^{15}$ verified that the increment of residual strain and the increase of plastic deformation decrease with each applied mechanical cycle.

\section{Conclusions}

The results of this work shows that the number of cycles contributes to the increase in residual strain, i.e, when the number of cycles increases the induction stress of the martensite transformation decreases. Part of the residual strain is associated with the retained martensite, that is, fraction of the stress-induced martensite that did not transform into austenite. For the alloy $\mathrm{Cu}-11.8 \mathrm{Al}-0.6 \mathrm{Be}-4 \mathrm{Nb}$ it was verified that the presence of precipitates rich in $\mathrm{Nb}$ was not a predominant factor for the increase of residual strain. The alloy $\mathrm{Cu}-11.8 \mathrm{Al}-0.6 \mathrm{Be}-4 \mathrm{Nb}$ showed reverse transformation temperatures higher than those presented by $\mathrm{Cu}-11.8 \mathrm{Al}-0.6 \mathrm{Be}-0.5 \mathrm{Nb}$ alloy. This fact is related to the large amount of precipitates rich in $\mathrm{Nb}$ present in the $\mathrm{Cu}$ 11.8Al-0.6Be-4Nb alloy. A saturation process occurs in the residual strain gain with the increase in the number of cycles for the alloys studied. The mechanical cycling showed as a efficient mechanism to increase the residual strain, and, consequently, the amount of martensite retained. However, the gain of residual strain is accompanied by an increase of plastic deformation.

\section{Acknowledgment}

This work was financially supported by the Brazilian National Council for Scientific and Technological Development$\mathrm{CNPq}$ and the Coordination for the Improvement of Higher Education Personnel-CAPES.

\section{References}

1. Li Z, Cao LF, Guo MX, Tang N, Fang M, Liu N. Deformation behavior of $\beta_{1}$ phase in polycrystalline CuAlMnZnZr shape memory alloy with wide transformation hysteresis. Materials Science and Engineering: A. 2005;403(1-2):227-233.

2. He XM, Zhao LZ, Zhang SF, Dou SW, Zhang RF. Study of the thermal physical properties of $\mathrm{Ti}_{47} \mathrm{Ni}_{44} \mathrm{Nb}_{9}$ wide hysteresis shape memory alloy. Materials Science and Engineering: $A$. 2006;441(1-2):167-169.

3. Piao M, Otsuka K, Miyazaki S, Horikawa H. Mechanism of the $\mathrm{A}_{\mathrm{s}}$ Temperature Increase by Pre-deformation in Thermoelastic Alloys. Materials Transactions, JIM. 1993;34(10):919-929.

4. Omori T, Wang JJ, Sutou Y, Kainuma R, Ishida K. Two-Way Shape Memory Effect Induced by Bending Deformation in Ductile Cu-Al-Mn Alloys. Materials Transactions. 2002;43(7):16761683.

5. Zhao X, Yan X, Yang Y, Xu H. Wide hysteresis NiTi(Nb) shape memory alloys with low $\mathrm{Nb}$ content (4.5 at.\%). Materials Science and Engineering: A. 2006;438-440:575-578.

6. Wei L, Zhao X. Mechanical Properties and Transformation Behavior of NiTiNb Shape Memory Alloys. Chinese Journal of Aeronautics. 2009;22(5):540-543.

7. Wang M, Jiang M, Liao G, Guo S, Zhao X. Martensitic transformation involved mechanical behaviors and wide hysteresis of NiTiNb shape memory alloys. Progress in Natural Science: Materials International. 2012;22(2):130-138.

8. Oliveira DF, Brito ICA, França FJC, Lima SJG, Melo TAA, Gomes RM. Assessment of Pipe Coupling by Using the Recovery of Stress-Induced Martensites in Superelastic Cu$11.8 \mathrm{Al}-0.6 \mathrm{Be}-0.5 \mathrm{Nb}$ Alloy. Journal of Materials Engineering and Performance. 2017;26(5):2264-2270. 
9. Saint-Sulpice L, Chirani SA, Calloch S. Superelastic behavior of shape memory alloys under proportional cyclic loadings. Materials Science and Engineering: A. 2008;481-482:174-177.

10. Oliveira JP, Zeng Z, Berveiller S, Bouscaud D, Fernandes FMB, Miranda RM, et al. Laser welding of $\mathrm{Cu}-\mathrm{Al}$-Be shape memory alloys: Microstructure and mechanical properties. Materials \& Design. 2018;148:145-152.

11. He XM, Rong LJ, Yan DS, Li YY. TiNiNb wide hysteresis shape memory alloy with low niobium content. Materials Science and Engineering: A. 2004;371(1-2):193-197.

12. Guniputi BN, Murigendrappa SM. Influence of Gd on the microstructure, mechanical and shape memory properties of Cu-Al-Be polycrystalline shape memory alloy. Materials Science and Engineering: A. 2018;737:245-252.

13. Malard B, Sittner P, Berveiller S, Patoor E. Advances in martensitic transformations in $\mathrm{Cu}$-based shape memory alloys achieved by in situ neutron and synchrotron X-ray diffraction methods. Comptes Rendus Physique. 2012;13(3):280-292.

14. Sedmák P, Šittner P, Pilch J, Curfs C. Evolution of Internal Stresses During Cyclic Superelastic Deformation of NiTi Investigated by X-ray Synchrotron Diffraction. Materials Today: Proceedings. 2015;2(Suppl 3):S731-S734.

15. Sedmák P, Šittner P, Pilch J, Curfs C. Instability of cyclic superelastic deformation of NiTi investigated by synchrotron X-ray diffraction. Acta Materialia. 2015;94:257-270.

16. Lelatko J, Morawiec $\mathrm{H}$. The effect of $\mathrm{Ni}$, $\mathrm{Co}$ and $\mathrm{Cr}$ on the primary particle structure in $\mathrm{Cu}-\mathrm{Al}-\mathrm{Nb}-\mathrm{X}$ shape memory alloys. Materials Chemistry and Physics. 2003;81(2-3):472-475.

17. Lelatko J, Morawiec N, Koval YN, Kolomyttsev VI. Structure and properties of high-temperature alloys with the effect of shape memory in the system Cu-Al-Nb. Metal Science and Heat Treatment. 1999;41(8):351-353.
18. Candido GVM, Melo TAA, Albuquerque VHC, Gomes RM, Lima SJG, Tavares JMRS. Characterization of a CuAlBe Alloy with Different Cr Contents. Journal of Materials Engineering and Performance. 2012;21(11):2398-2406.

19. Funakubo H. Shape Memory Alloys. New York: Gordon and Breach; 1984.

20. Wang S, Tsuchiya K, Wang L, Umemoto M. Martensitic stabilization and defects induced by deformation in TiNi shape memory alloys. International Journal of Minerals, Metallurgy, and Materials. 2011;18(1):66-69.

21. Saint-Sulpice L, Arbab-Chirani S, Calloch S. Thermomechanical cyclic behavior modeling of $\mathrm{Cu}-\mathrm{Al}-\mathrm{Be}$ SMA materials and structures. International Journal of Solids and Structures. 2012;49(9):1088-1102.

22. Olbricht J, Yawny A, Condó AM, Lovey FC, Eggeler G. The influence of temperature on the evolution of functional properties during pseudoelastic cycling of ultrafine grained NiTi. Materials Science and Engineering: A. 2008;481:142-145.

23. Cladera A, Weber B, Leinenbach C, Czaderski C, Shahverdi M, Motavalli M. Iron-based shape memory alloys for civil engineering structures: An overview. Construction and Building Materials. 2014;63:281-293.

24. He XM, Rong LJ. Effect of deformation on the stress-induced martensitic transformation in $\left(\mathrm{Ni}_{47} \mathrm{Ti}_{44}\right)_{100-x} \mathrm{Nb}_{\mathrm{x}}$ shape memory alloys with wide hysteresis. Metals and Materials International. 2006;12(4):279-288.

25. Montecinos S, Cuniberti A. Thermomechanical behavior of a $\mathrm{CuAlBe}$ shape memory alloy. Journal of Alloys and Compounds. 2008;457(1-2):332-336. 